\title{
Neural Network-Based Event-triggered Adaptive Asymptotic Tracking Control for Switched Nonlinear Systems
}

\section{Baomin Li}

Liaocheng University

Jianwei Xia ( $\square$ njustxjw@126.com )

Liaocheng University

Wei Sun

Liaocheng University

Hao Shen

Liaocheng University

Huasheng Zhang

Liaocheng University

\section{Research Article}

Keywords: Event-triggered control, neural network technique, unknown control directions, switched nonlinear systems

Posted Date: March 3rd, 2021

DOl: https://doi.org/10.21203/rs.3.rs-260899/v1

License: (c) (i) This work is licensed under a Creative Commons Attribution 4.0 International License. Read Full License 


\section{Abstract}

This paper addresses the event-triggered based adaptive asymptotic tracking control problem for switched nonlinear systems with unknown control directions based on neural network technique. A novel asymptotic tracking controller, in which Nussbaum functions are introduced to address the issue of unknown control directions, is designed by combining neural network control technology and eventtriggered strategy. Different from the existing tracking control schemes, the proposed controller in this paper can guarantee that the tracking error $\varsigma 1$ asymptotically converges to the origin and reduce the communication burden from the controller to the actuator. Finally, the effectiveness of the presented control design is proved by numerical examples.

\section{Full Text}

Due to technical limitations, full-text HTML conversion of this manuscript could not be completed. However, the latest manuscript can be downloaded and accessed as a PDF.

\section{Declarations}

\section{Conflict of interest:}

The authors declared that they have no conflicts of interest to this work. We declare that we do not have any commercial or associative interest that represents a conflict of interest in connection with the work submitted.

\section{Figures}



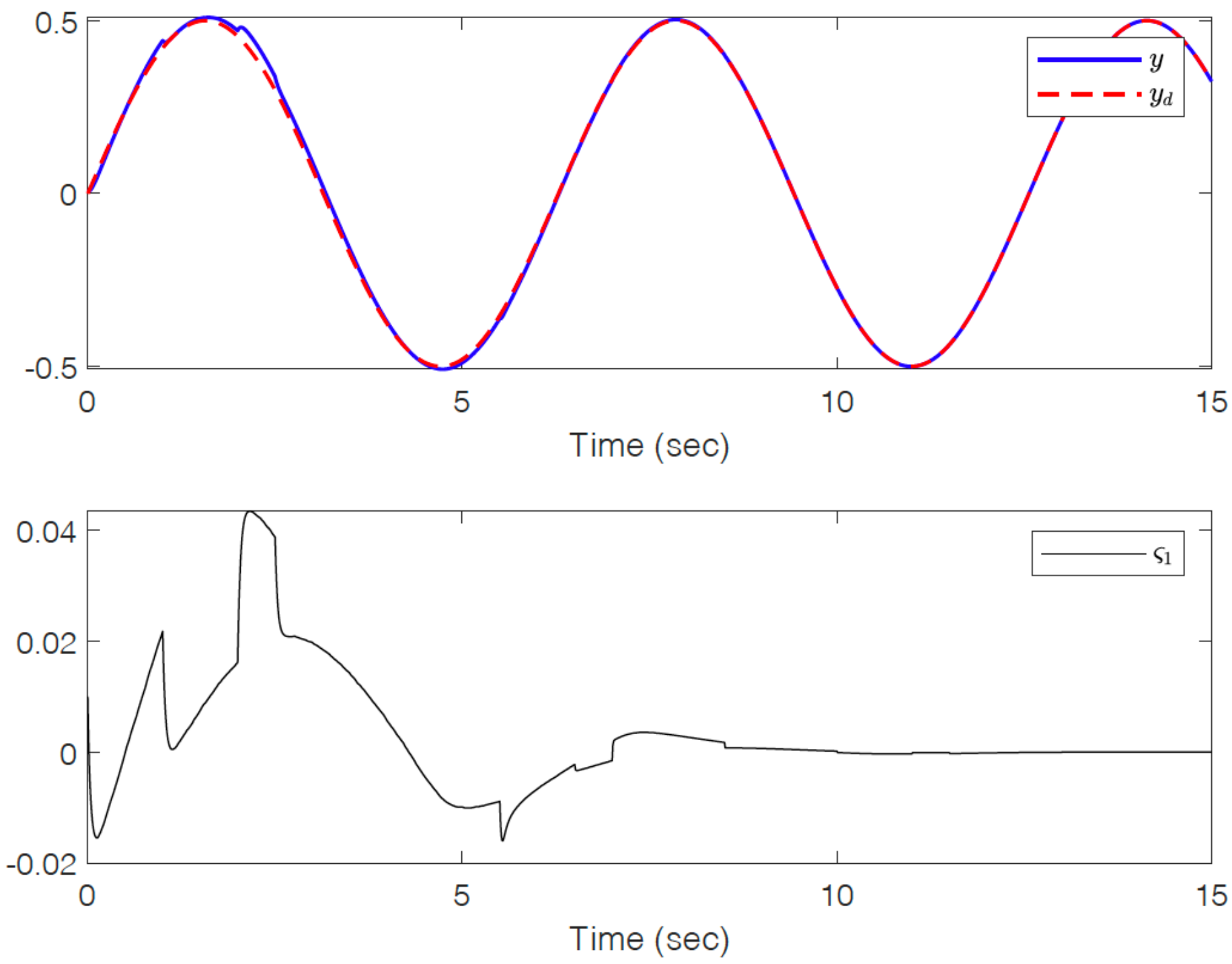

Figure 1

The trajectories of $y, y d$ and $\varsigma 1$. 


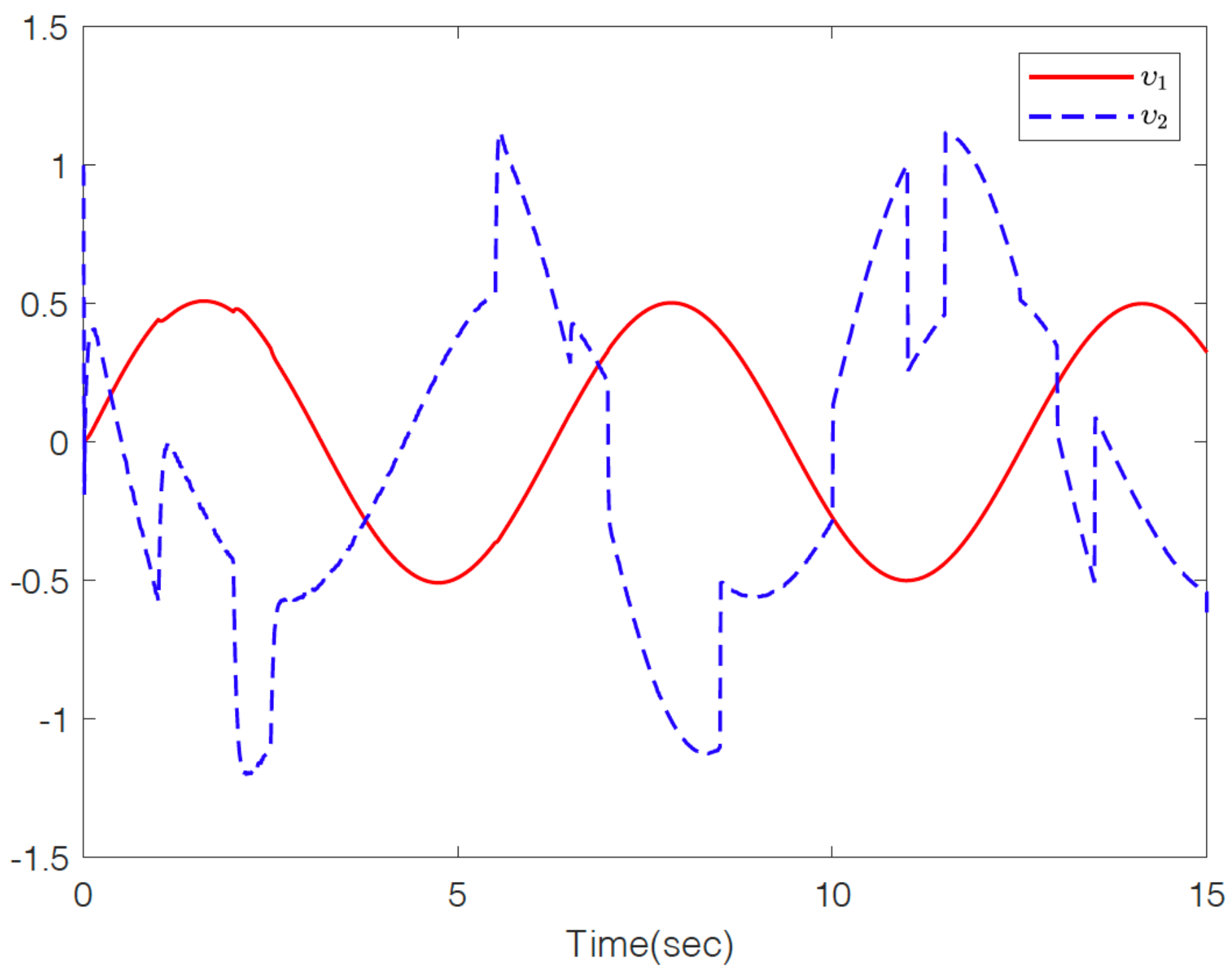

Figure 2

The trajectories of system states $₫ \mathrm{v} 1$ and $₫ \mathrm{v} 2$. 

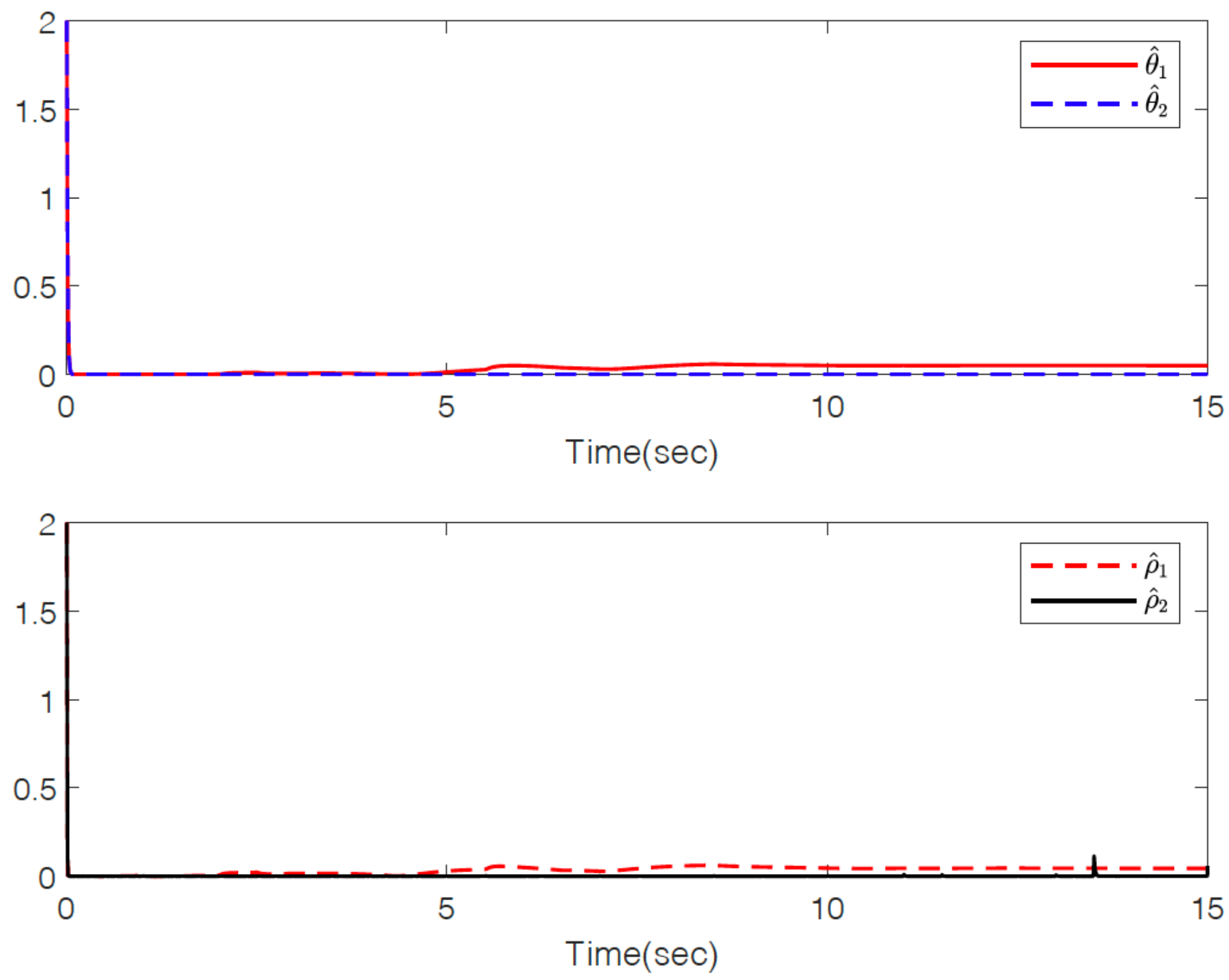

Figure 3

The trajectories of adaptive laws $\theta^{\wedge} \unrhd 1, \theta^{\wedge} \llbracket 2$, $\rho^{\wedge} \otimes 1$ and $\rho^{\wedge} \otimes 2$. [See manuscript PDF file for complete caption] 

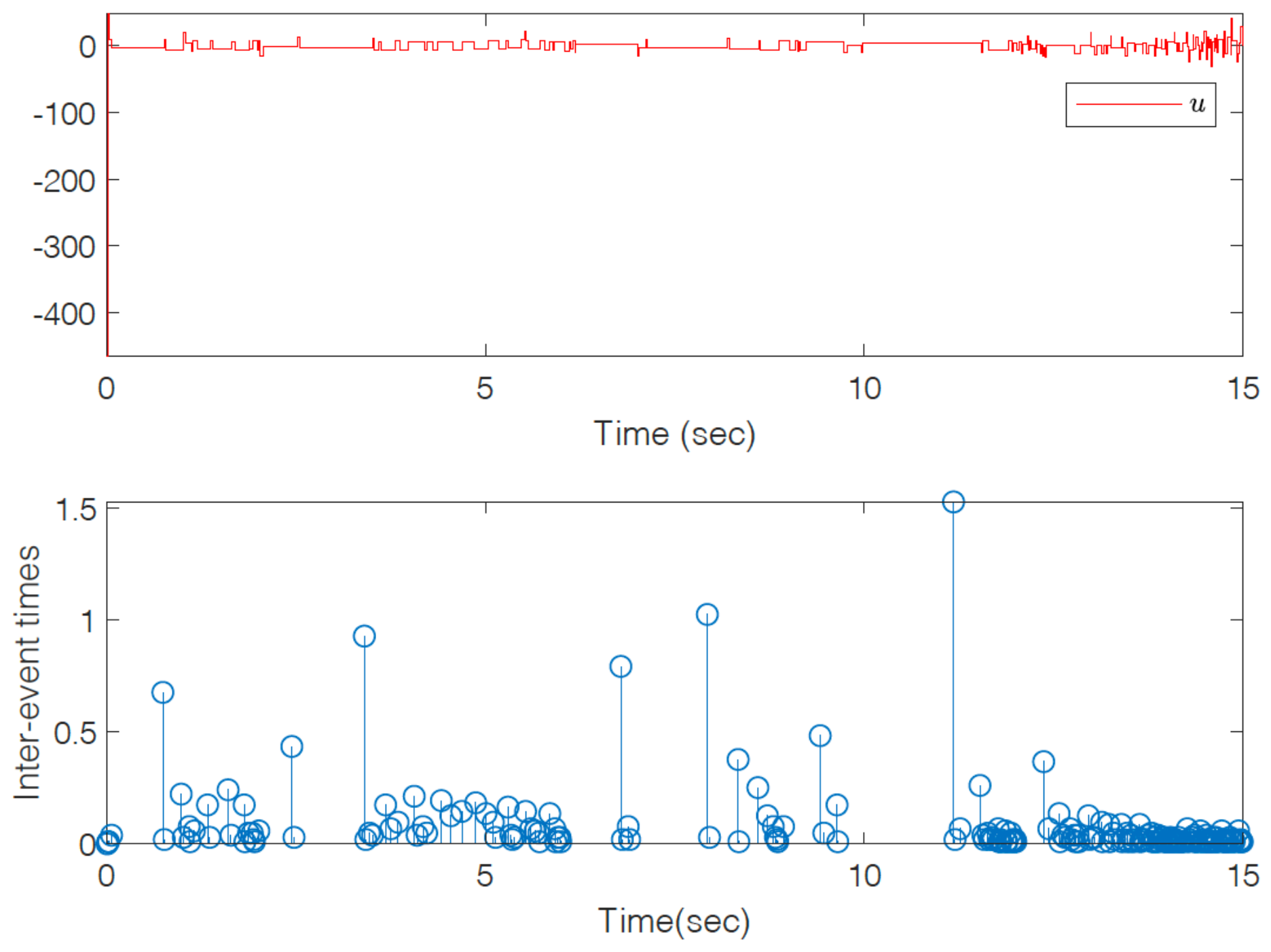

Figure 4

The trajectory of control input $u$ and trigger time interval. 


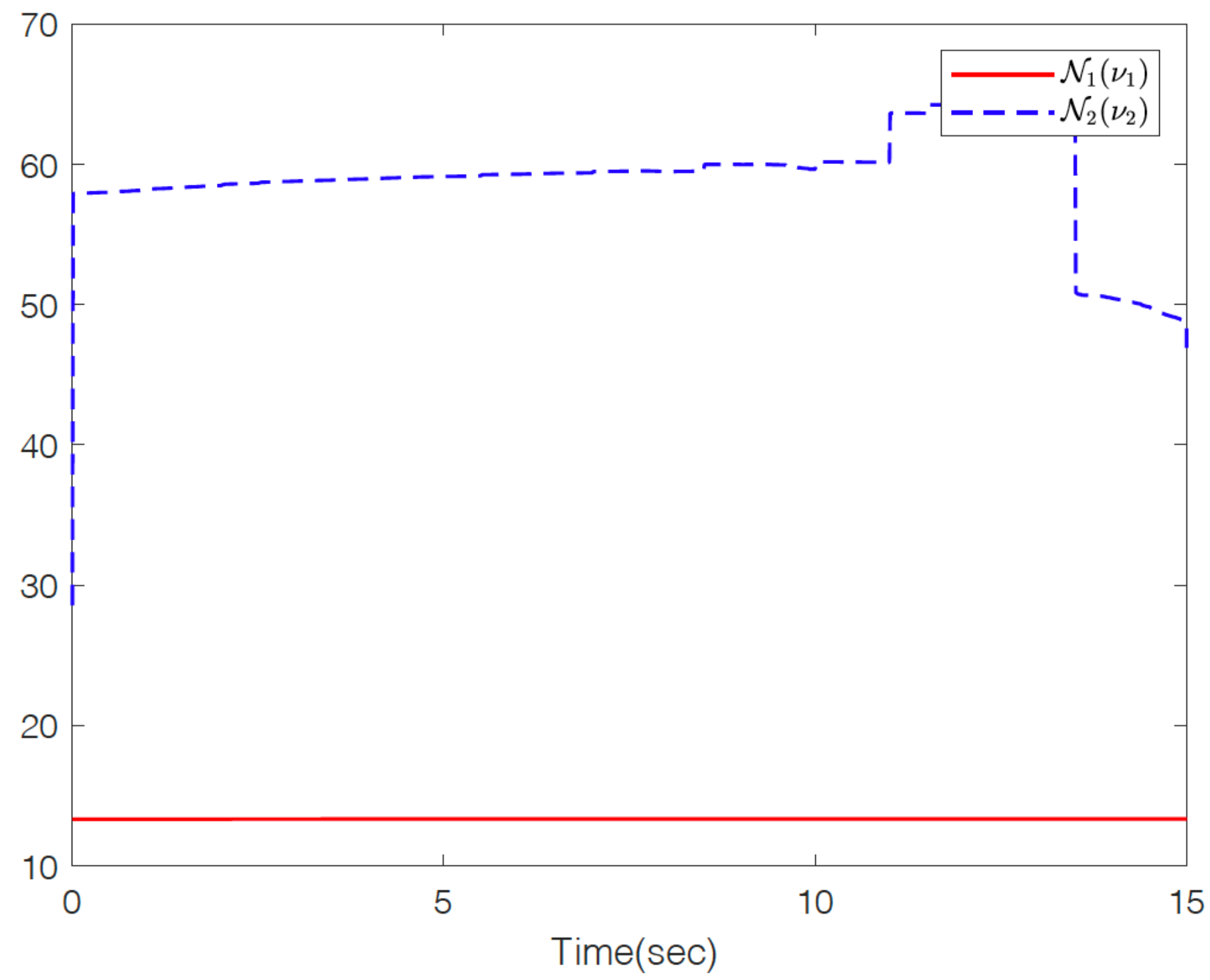

Figure 5

The trajectories of N1(v1) and N2(v2). 


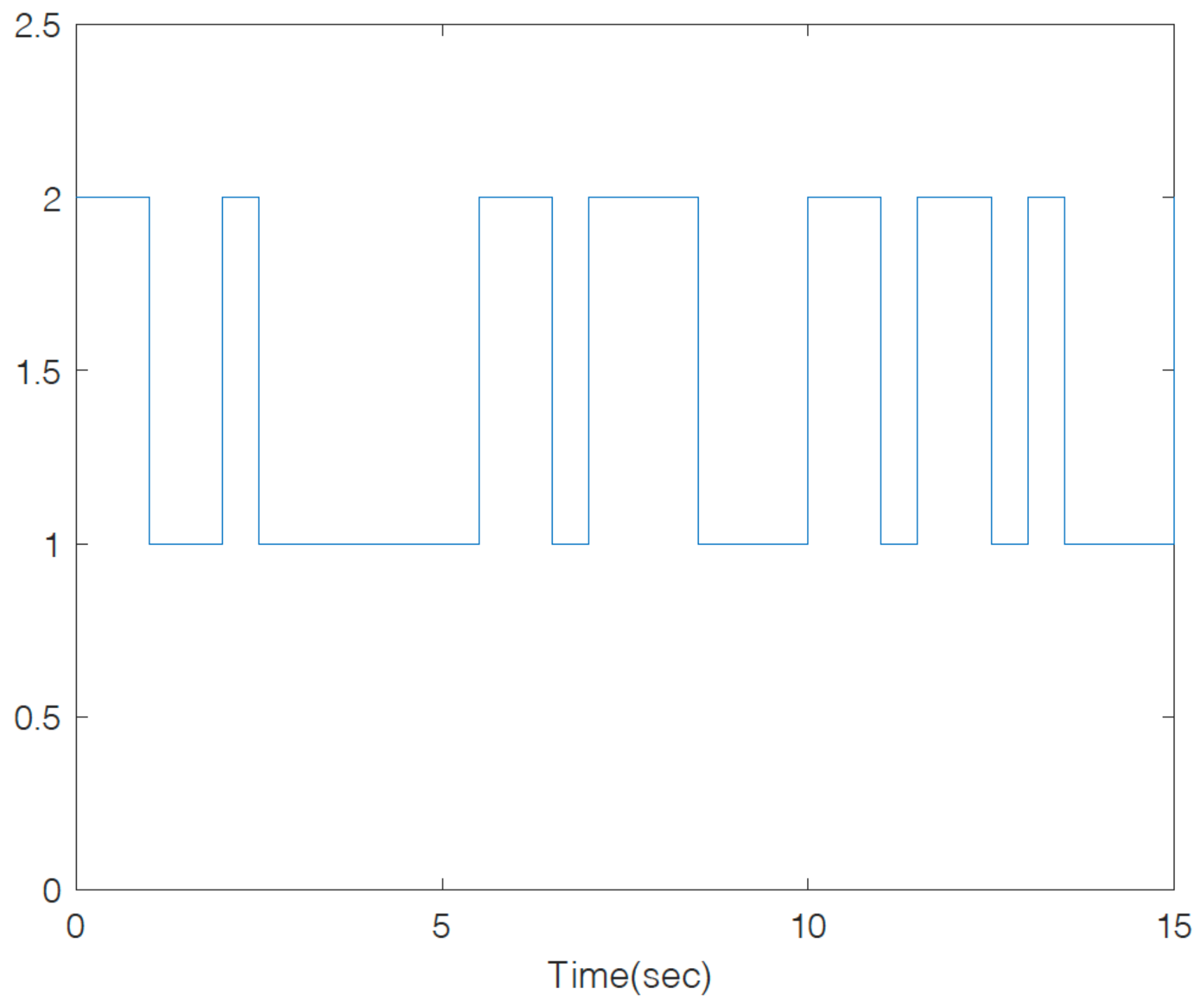

Figure 6

The trajectory of switching signal. 